\title{
ATENDIMENTO EDUCACIONAL ESPECIALIZADO E O ENSINO REGULAR: INTERLOCUÇÕES DOCENTES COM VISTAS À INCLUSÃO
}

\author{
ASISTENCIA EDUCATIVA ESPECIALIZADA Y ENSEÑANZA REGULAR: \\ ENSE NANZA DE INTERLOCUCIONES CON MIRAS A LA INCLUSIÓN
}

\author{
SPECIALIZED EDUCATIONAL ASSISTANCE AND REGULAR EDUCATION: \\ TEACHING OF INTERLOCUCIONES WITH A VIEW TO THE INCLUSION
}

\author{
Ilani Marques Souto ARAÚJO ${ }^{1}$ \\ Liliane Luz ALVES ${ }^{2}$ \\ Francisco Ricardo Miranda PINTO ${ }^{3}$ \\ Ilaneide Marques Souto BEZERRA ${ }^{4}$
}

RESUMO: A temática central deste texto é a inclusão no espaço escolar de uma minoria estigmatizada. Objetiva-se refletir como ocorre a interlocução entre professores da sala de Atendimento Educacional Especializado (AEE) e da sala de aula regular, na perspectiva da inclusão de pessoas com deficiência. Trata-se de um estudo do tipo descritivo com abordagem qualitativa, realizado em escolas do sistema público municipal de Sobral - CE, tendo como participantes 10 professores, utilizando-se para a coleta dos dados, o questionário. Os resultados evidenciam que os professores da sala de ensino comum e da sala de recurso multifuncionalAEE devem estar em constante sintonia, para que os objetivos traçados sejam alcançados, de forma que o trabalho seja interdisciplinar e colaborativo. É necessário instrumentalizar as instituições escolares para esse atendimento e investir na formação dos professores da sala de ensino comum e da sala recurso multifuncional-AEE, os quais devem promover o acolhimento e inclusão dessas crianças.

PALAVRAS-CHAVE: Inclusão. Professor. Atendimento educacional especializado

RESUMEN: El tema central de este texto es la inclusion en el espacio School de una debe ser minoritario estigmatizada. El objetivo es reflejar cómo se produce la interlocución entre los profesores de la sala de servicios educativos especializados (ESA) y el aula regular en la perspectiva de la inclusión de las personas con discapacidad. Se trata de un estudio descriptivo

${ }^{1}$ Universidade Estadual do Ceará (UECE), Sobral - CE - Brasil. Mestranda em Ensino na Saúde pela. Docente do Curso de Pedagogia do e Professora Formadora II da Universidade Estadual Vale do Acaraú pelo Programa Nacional de Formação de Professores (PARFOR). ORCID: 〈http://orcid.org/0000-0002-3341-4416>. E-mail: Ilanita12@hotmail.com

${ }^{2}$ Centro universitário (INTA-UNINTA), Sobral - CE - Brasil. Docente do Curso de Jornalismo. Mestrado em Comunicação e Semiótica (PUC/SP). Especialista em Teorias da Comunicação (UFC/CE). ORCID: <http://orcid.org/0000-0002-4510-1126>. E-mal: lilianeluz@gmail.com

${ }^{3}$ Universidade de Fortaleza (UNIFOR), Fortaleza - CE - Brasil. Doutorando e mestre em Saúde Coletiva. Docente do Curso de Pedagogia da Universidade Estadual Vale do Acaraú (UVA), do Centro Universitário INTA (UNINTA) e do Curso de Direito da Faculdade Alencarina de Sobral (FAL). ORCID: <http://orcid.org/0000-00030771-6266 >. E-mail: ricardomiranda195@gmail.com

${ }^{4}$ Universidade Estadual Vale do Acaraú (UVA), Sobral - CE - Brasil. Coordenadora Pedagógica na Rede Municipal de Itapipoca e Docente Formadora II da, pelo Programa Nacional de Formação de Professores (PARFOR). ORCID: <http://orcid.org/0000-0003-1589-1398>. E-mail:ilaneide@ hotmail.com 
con un enfoque cualitative llevado a cabo en el sistema público municipal de Sobral-CE, teniendo como participantes 10 profesores que implican el cuestionario para desempolvar los archivos. Los resultados son que los Teachers de la sala de enseñanza común y la habitación de AEE deben estar en Constant armonía, de idea que se Elise los Objetive, que el servicio sea interdisciplinario y Collaborative. Es necesario equipar a las instituciones escolares para este cuidado y, a inverter en la formación de los profesores en la sala de enseñanza común y la Room de asistencia educación especializada, que debe promocionar la recepción y la inclusion de estos niños.

PALABRAS CLAVE: Inserción. Profesor. Servicio educativo especializado.

ABSTRACT: The central theme of this text is the inclusion in the school space of a stigmatized minority. The objective is to reflect how the interlocution between teachers in the specialized Educational Service Room (ESA) and the regular classroom in the perspective of the inclusion of people with disabilities occurs. This is a descriptive study with a qualitative approach performed in schools of the municipal public system of Sobral-CE, having as participants 10 teachers using the questionnaire to collect the data. The results show that the teachers of the common teaching room and the AEE room must be in constant harmony, so that the goals are achieved, so that the work is interdisciplinary and collaborative. It is necessary to equip the school institutions for this care and, to invest in the training of teachers in the common teaching room and the specialized educational attendance room, which should promote the reception and inclusion of these children

KEYWORDS: Inserción. Professor. Specialized educational software.

\section{Introdução}

A nível mundial a Declaração de Salamanca de 1994 é tida como marco mundial na difusão da filosofia da Educação Inclusiva enquanto no Brasil é representado pela Política Nacional de Educação Especial na perspectiva da Educação Inclusiva com o compromisso de incluir os alunos com deficiência na escola regular que a partir de então passou a ter a responsabilidade de ofertar o acesso igualitário entre todos os estudantes, sem distinção de sua condição física se dito 'normal' ou com deficiência (BRASIL, 2008).

Apesar desse avanço, ainda prevalece um forte debate acerca das vantagens e desvantagens da inclusão escolar. Sob esse prisma, são encontradas, hoje, práticas e pressupostos distintos, o que garante um consenso apenas aparente e acomoda diferentes posições que podem ser extremamente divergentes.

Ainda que a lei tenha sido instituída não fora, tão menos é, garantia para que a inclusão escolar seja efetivada, pois esta deve ser observada e vivenciada sem separação ou qualquer outro conceito de diferenciação compreendendo que esta, só existe, efetivamente, quando é 
propiciada uma educação em um mesmo contexto escolar, de todas as crianças, quer tenha ou não alguma deficiência, significando com isso, nunca negar as dificuldades de aprendizagem dos estudantes.

Nessa perspectiva as diferenças em um processo educacional não devem ser vistas como problemas, mas sim como diversidades que devem priorizar as distintas interações, pois como já preceitua Vigotsky (2007) é através das interações sociais que verdadeiramente a aprendizagem acontece, pela oportunidade de convivência social de todas as crianças em um mesmo ambiente.

Para isso, dois profissionais são essenciais para garantir a efetivação de um desenvolvimento pleno construção da autonomia das crianças com deficiência: o professor da sala de ensino regular e o terapeuta educacional da sala de recurso multifuncional do atendimento educacional especializado.

Frente ao exposto, configura-se o objetivo traçado de refletir como ocorre a interlocução entre professores da sala de Atendimento Educacional Especializado (AEE) e da sala de aula regular na perspectiva da inclusão de pessoas com deficiência.

Cabe enfatizar aqui, que o Atendimento Educacional Especializado (AEE), é um "conjunto de atividades e recursos pedagógicos e de acessibilidade, organizados institucionalmente, prestado de forma complementar ou suplementar à formação dos estudantes público alvo da educação especial, matriculados no ensino regular” (BRASIL, 2013, p.7).

Os diferentes contatos profissionais dos pesquisadores com as diferentes realidades e dicotomias da inclusão no âmbito educacional e como esta interfere direta ou indiretamente no campo da qualidade de vida das pessoas com deficiência e, principalmente, no respeito aos direitos humanos justificam o estudo que tem como problemática central: inquietações tais "Como ocorre a comunicação entre os professores do AEE e da sala regular na perspectiva da inclusão? Como esse contato entre profissionais aumenta a procura dos estudantes com deficiência?

Aponta-se que o estudo seja relevante por apresentar práticas pedagógicas no espaço escolar, que tem como principal interesse promover a inclusão e assim não apenas o desenvolvimento cognitivo, motor, emocional e social, como também, o respeito ao direito à Educação reconhecida como bem social. 


\section{Metodologia}

O estudo é do tipo descritivo-exploratório com abordagem qualitativa, pois debruça-se no mundo das relações humanas, especialmente um lado imperceptível e não captável em equações (MINAYO, 1998). Realizada no período de agosto a novembro no ano de 2017, em escolas da zona urbana, no espaço geográfico de Sobral, localizado na Zona Norte do Estado do Ceará, distante aproximadamente $250 \mathrm{~km}$ da capital, Fortaleza, tendo como universo, os docentes que compõem a Secretaria da Educação do Município de Sobral.

O universo da pesquisa foi a Rede de Educação Pública de Sobral com toda a sua estrutura humana e física. Os participantes da pesquisa são os professores que atendem aos critérios de inclusão que foi serem estatutários, com lotação em salas de recurso multifuncionalAEE ou regular, com estudantes em atendimento no AEE visto que nem todas as escolas municipais dispõe da oferta da Sala de Recurso multifuncional-AEE sendo essa condição considerada para a seleção aleatória dos participantes que perfez 10 participantes, 05 de sala regular e 05 de Sala de Recurso Multifuncional-AEE. Como critério de exclusão pontuou-se a desorientação espaço temporal na hora de responder ao questionário. Aplicados os critérios ao universo de todos os participantes perfazendo 10 .

Para a coleta de dados, foram realizadas diferentes técnicas como visitas, observação nas Salas Recurso Multifuncional - AEE, ainda, nas salas de ensino comum e aplicado uma entrevista com três questões abertas. Para preservar a identidade dos participantes os mesmos serão identificados como P1, P2, P3, P4 e P5 e PAEE1, PAEE2, PAEE3, PAEE4 e PAEE5. À participação deles optou-se por fazer as correções de Língua Portuguesa, apresentando os resultados de forma a refletir com a literatura pertinente a área.

Salienta-se que todos os passos desta pesquisa respeitaram os aspectos éticos pertinentes a estudos com seres humanos, balizados pela lei 466/2012 e resguardados pela Resolução $510 / 2016$.

\section{Resultados e discussão}

A pesquisa caracteriza por uma intenção de analisar a mudança de paradigmas, costumes e conceitos arraigados em velhas práticas educacionais.

Sabidamente ainda têm lugar nas propostas pedagógicas contempladas em muitas instituições escolares, assim como nas práticas docentes, um olhar deturpado que infelizmente, ainda enxerga o estudante com deficiência como sendo diferente e que deve ser tratado de forma 
diferente ferindo a Constituição Federal de 1988 que afirma ser a educação um dever do Estado, um direito do cidadão, e que esta deve contemplar igualdade por sua condição de acesso e permanência, sem distinção de qualquer natureza, sendo preceito inalienável, a igualdade de todos perante a lei (BRASIL, 1988).

Nessa perspectiva, foi indagado sobre as considerações acerca do processo de inclusão das crianças com deficiência no ensino regular. As respostas foram semelhantes no sentido de que muito ainda se falta para o verdadeiro "incluir", no entanto, apontam fatores que diferem as respectivas ideias.

A Lei de Diretrizes e Bases da Educação Nacional (LDBEN) № 9.394/96 já preconiza em seu Art. 59 que "os sistemas de ensino devem assegurar aos alunos com deficiência currículo, métodos, recursos e organização específicos para atender às suas necessidades, contemplando nesses espaços profissionais com conhecimento e formação adequada a lidar com essas demandas" (BRASIL, 2013).

Acredita-se, embasados em estudos, que essa, seja a maior política pública ativa no Brasil com olhar voltado a inclusão de pessoas com deficiência na Educação, mas que sozinha ainda não é efetiva (OLIVEIRA, 2017), como podemos observar nas falar abaixo:

P1: [...] necessárias políticas públicas mais efetivas, no sentido da assistência, [...] somente o apoio da professora de AEE ainda não é suficiente para o resultado esperado, é necessária uma equipe de profissionais especializados. P2 Não basta matricular os alunos com deficiência no ensino regular e ofertar um atendimento educacional especializado, é necessário um apoio transdisciplinar.

As realidades apontadas pelas participantes aproximam-se do que fora identificado por Greguol, Malagodi e Carraro (2018) em seu estudo com professores de Educação Física, que observam a necessidade da equipe multidisciplinar para o processo de inclusão, ou ainda com o texto de Camargo (2018) onde o autor mostra que se faz necessário que as metodologias, materiais e instrumentos tenham alcance aos princípios da diversidade evitando homogeneizar as ações pensando em salas de aulas únicas.

Essa ideia encontra escopo nas palavras de Sant'Ana (2005), que assinalou que a história do pensamento educacional confirma que o fato desses alunos estarem no mesmo espaço com os demais não quer dizer que estejam realmente incluídos, tendo em visto que, a inclusão implica práticas escolares que proporcionem relações significativas dentro da perspectiva de aprendizagem colaborativa, capazes de remover barreiras ao acesso e à participação dessas pessoas na aprendizagem e na sociedade.

Nessa mesma linha Mazzotta e D’Antino (2011, p. 47), mostram que as políticas de 
inclusão de alunos na rede regular de ensino não consistem na permanência física desses estudantes em pretensas escolas, com estrutura física adequada, mas que estas necessitam de todo o suporte técnico e didático-pedagógico adequado às pessoas com deficiência.

A PAEE3 pontuou que a inclusão está no caminho certo, ressaltando a parceria que tem com o grupo gestor e todos os professores de sala, no sentido de efetivar ações inclusivas diariamente no ambiente escolar e não apenas dentro da sala de AEE.

Hoje está bem diferente de uns anos atrás, porque temos a liberdade de discutir ideias para melhorar o desenvolvimento das crianças com deficiência e sentir o apoio do grupo escolar.

P3: A inclusão é uma realidade que precisa ser aperfeiçoada

P5 O trabalho do cuidador com os alunos com deficiência ajuda muito na prática

De acordo com as falas, sendo sua realidade compatível com o que é colocado na Política Nacional de Educação Especial na Perspectiva da Educação Inclusiva é tarefa dos sistemas de ensino disponibilizar as funções de instrutor, tradutor/intérprete de Libras e guiaintérprete, bem como de monitor ou cuidador dos estudantes com necessidade de apoio nas atividades de higiene, alimentação, locomoção, entre outras, que exijam auxílio constante no cotidiano escolar.

Pertinente ao que fora pontuado por PAEE3 o estudo de Oliveira e Cordeiro (2018), realizado com equipes diretivas em Santa Catarina, ainda há pouco entendimento por parte dos diretores sobre o que efetivamente é o AEE o que para este estudo se revela como ponto positivo perceber que os núcleos gestores da rede municipal se encontram com outros olhares e perspectivas.

Ressalta-se ainda que todas as professoras da sala de AEE foram unânimes em afirmar que, apesar de todos os percalços, o trabalho desenvolvido é realmente incluir. Apontaram que utilizam recursos diversos para oportunizar os alunos a conviverem em condições de igualdade com os demais alunos.

A segunda pergunta indagada ao grupo de professoras foi referente às principais barreiras enfrentadas no processo de inclusão no cotidiano escolar, pois, entende-se que são muitas no dia-a-dia das escolas para incluir efetivamente as crianças com deficiência no ensino regular. Refere-se como barreira os obstáculos, atitudes ou comportamentos que dificultem ou impeçam a partição social de um indivíduo, assim como também à liberdade de movimento e de expressão, comunicação, informação, segurança.

Observou-se que a acessibilidade, apesar de tantas discussões no contexto atual ainda deixa a desejar. Dos 10 participantes, 04 abordaram que têm dificuldades ainda na parte da 
estrutura da escola tanto física, quanto de recursos didático específicos para esse alunado. No processo de inclusão escolar, existem alguns educandos que precisam de auxílio e mediação em tempo integral dentro das salas de aula.

Para Pelosi e Nunes (2009), alunos com déficits motores e intelectuais mais graves muitas vezes não são capazes de falar para responder às solicitações do professor, não escrevem com autonomia e são dependentes em sua mobilidade e autocuidado, mas esses mesmos alunos podem aprender e se expressar se lhes for oferecida maior acessibilidade indo de encontro ao que preceitua o teórico Howard Gardner quando aponta a Teoria das Inteligências Múltiplas em uma perspectiva de que a pessoa pode desenvolver com pelo menos 10 diferentes saberes (GARDNER, 1995) e que o fato dela ter deficiência não a encarcera em um modelo específico.

Por isso há a necessidade de se pensar a respeito dessas técnicas, recursos e profissionais que possam auxiliar estes alunos a se desenvolverem da melhor maneira possível. Nesse sentido "o conhecimento da Tecnologia Assistiva e os serviços de apoio tornaram-se fundamentais para o processo de inclusão escolar" (PELOSI; NUNES, 2009).

As barreiras atitudinais também foram ressaltadas pela PAEE2 que enfatizou:

As próprias famílias que ainda agem com certos tipos de preconceitos e muitas vezes não aceitam as crianças participarem de atividades juntamente com os outros alunos, impedindo assim a participação social da criança com deficiência em igualdade de condições, tão importante para o seu desenvolvimento.

Sobre esses mesmos aspectos a P5 também demonstrou insatisfação em algumas atitudes das famílias ao relatar que "[...] alguns pais consideram o filho com deficiência como um ser incapaz, e assim, os privam de algumas atividades que podem ser benéficas para o convívio com outras crianças.”, sendo insatisfação, também da P3 além de não cumprirem com as orientações pedagógicas e médicas deixando que as crianças não venham ao AEE.

A LDB institui que o AEE deve ser estabelecido sob a responsabilidade da escola atendendo as necessidades específicas de cada aluno, realizada no contra turno sem prejuízo da participação desses alunos nas demais atividades escolares (BRASIL, 2013).

A Lei 13.146 (BRASIL, 2015, p. 02) traz em seus dispositivos a classificação de barreiras existentes que devem ser enfrentadas. São elas: as barreiras urbanísticas, arquitetônicas, transportes, comunicação, atitudinais e tecnológicas (BRASIL, 2015, p. 02).

a) barreiras urbanísticas: as existentes nas vias e nos espaços públicos e privados abertos ao público ou de uso coletivo;

b) barreiras arquitetônicas: as existentes nos edifícios públicos e privados;

c) barreiras nos transportes: as existentes nos sistemas e meios de 
transportes; barreiras nas comunicações e na informação: qualquer entrave, obstáculo, atitude ou comportamento que dificulte ou impossibilite a expressão ou o recebimento de mensagens e de informações por intermédio de sistemas de comunicação e de tecnologia da informação;

d) barreiras atitudinais: atitudes ou comportamentos que impeçam ou prejudiquem a participação social da pessoa com deficiência em igualdade de condições e oportunidades com as demais pessoas;

e) barreiras tecnológicas: as que dificultam ou impedem o acesso da pessoa com deficiência às tecnologias;

Na prática, evidencia-se que o dispositivo legal faz uma abordagem real das barreiras que devem ser transpostas para uma efetiva inclusão no contexto da sala de aula.

Outra dificuldade apontada por uma $\mathrm{P} 4$ é referente à sua formação para lidar com casos tão específicos de crianças com deficiência. Para ela, embora tenha o apoio da gestão e da professora do AEE, sempre se sente insegura por não saber todas as vezes como agir:

Nós professores de alunos especiais teríamos que ter uma formação mais específica que nos direcionasse de forma mais precisa, no ano passado tive em minha aula uma criança com deficiência visual e agora tenho um com deficiência intelectual, não me sinto tão preparada.

O que se percebe apesar do crescente número de formações nos últimos anos é que ainda há um déficit significativo de profissionais capacitados em lidar com essa clientela. Guasselli (2012) alerta para a ausência de uma política séria e efetiva de educação inclusiva na maioria dos sistemas escolares, os quais apresentam processos de rupturas, descontinuidades e ausência de formação continuada de docentes que seja adequada às políticas educacionais.

Monico, Morgado e Orlando (2018) apontam em seu estudo sobre a Educação Especial e Inclusiva nos Programas de Pós-Graduação que esta temática ainda sofre de enorme carência nos anos que vão de 2009 a 2013. Semelhança, só que voltado ao Ensino Superior, é apresentado por Bazon et al. (2018) ao identificar baixos índices de formação voltados para a Educação Especial e Inclusiva entre professores universitários de duas instituições federais localizadas em São Paulo e Minas Gerais.

Os dados desvelam que ainda não tem a real visibilidade a formação de professores na perspectiva da Educação Inclusiva o que pode comprometer a forma como as aulas são ministradas e como ocorre a interlocução entre os profissionais das duas salas - regular e AEE - na perspectiva de incluir os estudantes com deficiências. Para depreender esse conhecimento a terceira pergunta voltou-se para a articulação entre as propostas de inclusão trabalhadas pelos professores da sala comum e da sala de AEE.

Houve unanimidade em afirmar que há a busca constante pela sintonia para que os objetivos traçados para os alunos com deficiência sejam alcançados, através do trabalho seja 
interdisciplinar e colaborativo. Cabe aqui ressaltar que ao professor da sala de aula comum é atribuído o ensino das áreas do conhecimento e ao professor da sala de Recurso MultifuncionalAEE vale complementar a formação do estudante com conhecimentos e recursos específicos que eliminem as barreiras as quais impedem ou limitam sua participação com autonomia e independência nas turmas comuns do ensino regular (BRASIL, 2010).

Para Mousinho et al.(2010), a parceria entre os profissionais da escola oportuniza o estabelecimento de metas realistas no que se refere ao desenvolvimento, como também possibilita avaliar o educando de acordo com suas próprias conquistas. Nesse sentido, o professor da dala de recurso multifuncional - AEE deve ser um parceiro do professor da sala de ensino comum.

Sobre esses aspectos a PAEE4 balizou que reconhece a diferença entre as funções, pois o professor do AEE, identifica, elabora e organiza recursos pedagógicos e de acessibilidade, mas não considera em nenhum momento que esse trabalho deve ser individual, pois “[...] o trabalho de um, depende do trabalho do outro.", reconhecendo no professor de AEE um mediador do desenvolvimento do aluno com deficiência, sendo responsável ainda por auxiliar os outros professores e toda a equipe pedagógica no trabalho com esse público.

Para a P5, as propostas entre o professor de AEE e da sala de ensino comum devem estar sempre alinhadas, embora que cada um mantenha suas funções específicas: "Aqui na Escola, mesmo com toda correria, sempre arrumo um tempo para conversar com a professora do AEE, sempre busco ajuda porque pra mim é muito difícil desenvolver estratégias para ajudar meus alunos com deficiência".

Aduz-se diante das questões colocadas que a inclusão é uma realidade vivenciada dentro das escolas, no entanto, é necessário ainda uma política mais efetiva e um processo de conscientização por parte de todos que permeiam a sociedade. A mesma deve englobar todos os indivíduos, independentemente de sua condição física ou psicológica, pois de acordo com a Política Nacional de Educação Especial na perspectiva da Educação Inclusiva (BRASIL, 2008), todos têm o direito a aprender e a se desenvolver em qualquer escola, a qual deve respeitar as diferenças, limites e facilidades de cada estudante.

Por essa razão, urge a necessidade de estruturar cada vez mais as escolas para facilitar que as políticas inclusivas sejam seguidas e caracterizar o papel de cada profissional no processo de inclusão, para assim poder ajudar os alunos com deficiência a se desenvolverem suas potencialidades.

Entretanto não podemos deixar de apontar que com o advento da internet, aplicativos estão sendo pensados, para a melhoria do desempenho do educando com deficiência. Podemos 
trazer o aplicativo chamado "Gulia", como é chamado, criado por uma amazonense que possui o mesmo nome do aplicativo, entrou em funcionamento em julho de 2018 e em novembro do mesmo ano já tinha mais de 5 mil downloads, o aplicativo transforma o movimento da libras em mensagem de áudio e traduz o áudio em movimentos de libras. Portanto acreditamos que ao se tornar o uso do aplicativo em sala de aula, possa assim, corroborar com o desenvolvimento escolar dos alunos com deficiência.

Entende-se como limitações desse estudo a escassez de textos na literatura nacional que abordem de forma específica a temática desse estudo.

\section{Considerações finais}

A proposta de uma sociedade inclusiva, baseada numa filosofia que reconhece e valoriza a diversidade, vem sendo discutida e instituída com o tempo e inserida no dia a dia da população em geral. Este processo inclusivo e as transformações geradas nas escolas ou nas ideologias das pessoas e nos paradigmas da educação, já começaram a cobrar mudanças. A grande questão é como facilitar para que ocorra de fato um processo de inclusão das crianças com deficiência no ensino regular.

Observou-se com essa pesquisa que as políticas de inclusão de alunos com deficiência na rede regular de ensino não consistem somente na permanência física desses alunos junto aos demais educandos, é muito mais que isso, tendo em vista, que representa a ousadia de rever concepções e paradigmas, bem como desenvolver o potencial dessas pessoas, respeitando suas diferenças e atendendo suas fragilidades.

Frente a isso, constata-se a necessidade de construir em cada profissional da comunidade escolar, um novo olhar sobre os sujeitos, rompendo com a visão de que a deficiência é o fim e passando a enxergar estes alunos pelas suas potencialidades. A esses profissionais cabe ainda a função de buscar estratégias que despertem e desenvolvam competências, propondo conteúdos compatíveis com as experiências vividas pelos discentes para que atribuam significados ao que é repassado, objetivando participação ativa e interativa entre os pares.

Verificou-se, portanto, que o trabalho de parceria entre os professores da sala comum e da sala de recurso multifuncional-AEE deve estar em constante sintonia, para que os objetivos traçados sejam alcançados, de forma que o trabalho seja interdisciplinar e colaborativo. Essa interlocução garante o estabelecimento de metas palpáveis e reais, no que se refere ao desenvolvimento, como também possibilita avaliar o educando com deficiência de acordo com 
suas conquistas.

\section{REFERÊNCIAS}

BRASIL. Política nacional de educação especial na perspectiva da educação inclusiva. Disponível em http://portal.mec.gov.br/index.php?option=com_docman\&view=download\&alias=16690politica-nacional-de-educacao-especial-na-perspectiva-da-educacao-inclusiva05122014\&Itemid=30192. Acesso em 24 de maio de 2019.

BRASIL. Ministério da Educação. Secretaria de Educação Especial. Marcos Político-Legais da Educação Especial na Perspectiva da Educação Inclusiva. Brasília: Secretaria de Educação Especial, 2010.

BAZON, F. V. M. et al. Formação de formadores e suas significações para a educação inclusiva. Educ. Pesqui., São Paulo, v. 44, 2018. Acesso em: 30 abr. 2019.

CAMARGO, E. P. Inclusão social, educação inclusiva e educação especial: enlaces e desenlaces. Ciênc. educ., Bauru, v. 23, n. 1, p. 1-6, mar., 2017. Acesso em: 30 abril 2019.

GREGUOL, M.; MALAGODI, B. M.; CARRARO, A. Inclusão de Alunos com Deficiência nas Aulas de Educação Física: Atitudes de Professores nas Escolas Regulares. Rev. bras. educ. espec., Bauru, v. 24, n. 1, p. 33-44, mar., 2018. Acesso em: 30 abril 2019.

MARQUES DE OLIVEIRA, N. D. M.; CORDEIRO, A. F. M. O que pensam as equipes diretivas escolares sobre o Atendimento Educacional Especializado (AEE). Educ. rev.[online], v. 34, 2018. Acesso em: 20 abril 2019

MAZZOTTA, M.J.S; D’ANTINO, M.E.F. Inclusão social de pessoas com deficiências e necessidades especiais: cultura, educação e lazer. Saúde e Sociedade. São Paulo, v.20, n.2, p. 377-389, 2011.

MONICO, P. A.; MORGADO, L. A. S; ORLANDO, R. M. Formação inicial de professores na perspectiva inclusiva: levantamento de produções. Psicol. Esc. Educ., Maringá, v. 22, n. esp., p. 41-48, 2018. Acesso em: 30 abr. 2019.

MOUSINHO, R; SCHMID, E; MESQUITA, F; PEREIRA, J; MENDES, L; SHOLL, R.; NÓBREGA, V. Mediação Escolar e inclusão: revisão, dicas e reflexões. Revista de Psicopedagogia, São Paulo, v. 27, n. 82, p. 02-08, 2010. Acesso em: 22 nov. 2017. PELOSI, M. B.; NUNES, L. O. P. Caracterização dos professores itinerantes, suas ações na área de tecnologia assistiva e seu papel como agente de inclusão escolar. Revista Brasileira de Educação Especial, Marília, v.15, n.1, p. 141-154, 2009. Acesso em: 28 jul. 2018. 


\section{Como referenciar este artigo}

ARAÚJO, Ilani Marques Souto; ALVES, Liliane Luz; PINTO, Francisco Ricardo Miranda; BEZERRA, Ilaneide Marques Souto. Atendimento educacional especializado e o ensino regular: interlocuções docentes com vistas à inclusão. Revista on line de Política e Gestão Educacional, Araraquara, v. 23, n. 2, p. 441-452, maio/ago., 2019. E-ISSN:1519-9029. DOI: 10.22633/rpge.v23i2.12651

Submetido em: 10/03/2019

Revisões requeridas: 15/04/2019

Aprovado em: 06/05/2019

Publicado em: 09/06/2019 